\title{
Endoscopic vacuum therapy for esophageal anastomotic leak: combining guidewire with overtube technique
}

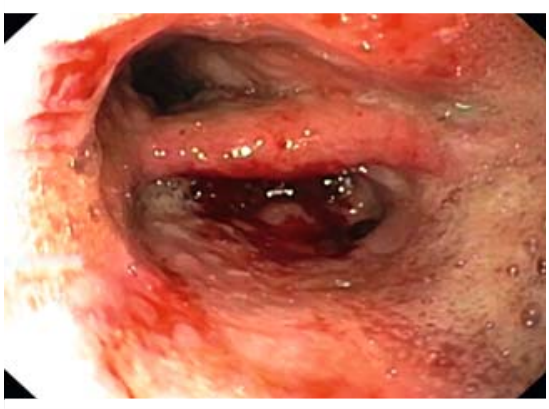

- Fig. 1 Anastomotic leak with an associated 5-cm cavity.

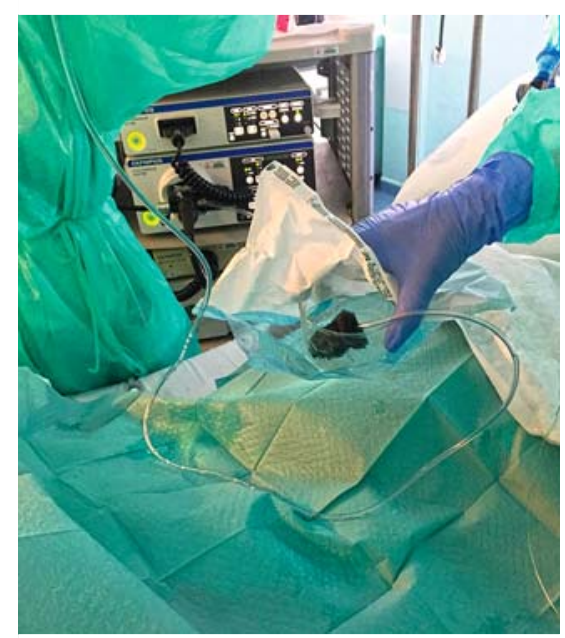

- Fig. 2 Open-pore polyurethane foam attached to a nasogastric tube.

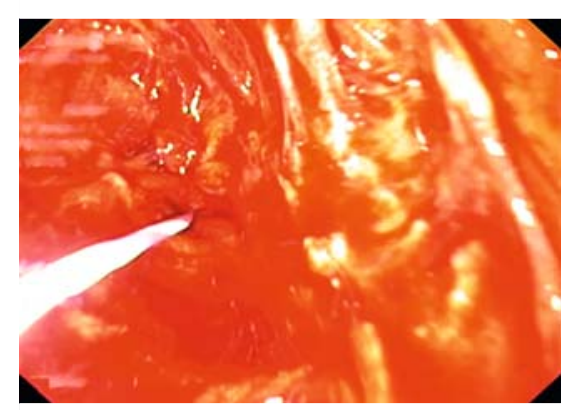

> Fig. 3 Insertion of the guidewire into the deepest point of the cavity.
A 70-year-old man with an adenocarcinoma of the gastroesophageal junction developed an anastomotic leak three weeks after Ivor Lewis esophagectomy. Initially, a fully covered metal stent was placed, but after stent redraw, endoscopy revealed the persistence of the leak and an associated $5-\mathrm{cm}$ cavity ( $\bullet$ Fig. 1 ). Endoluminal vacuum-assisted therapy was then considered. Since at that time there were no available kits in our country for this procedure in the upper gastrointestinal tract, open-pore polyurethane foam attached to a nasogastric tube (NGT) was used ( $\bullet$ Fig. 2 ).

During the procedure, the sponge must be inserted into the deepest point of the cavity, which is the most demanding part of the procedure. There are several methods for sponge placement [1]: a) advancing or pulling with grasping forceps [2]; b) using the piggyback method, where a suture loop secured to the tip of the NGT is grasped with endoscopic forceps and passed into the cavity [3]; c) placing the sponge through an overtube $[2,4]$; and d) passing the sponge into the esophagus using a rendezvous technique [5]. Regardless of the method used, the final position of the foam frequently needs to be adjusted endoscopically.

In this case we used a modified overtube technique ( $\vee$ Video 1$)$. The overtube was placed proximal to the cavity. A guidewire was advanced into the deepest point of the cavity ( $\bullet$ Fig. 3 ). The sponge attached to the nasogastric tube was

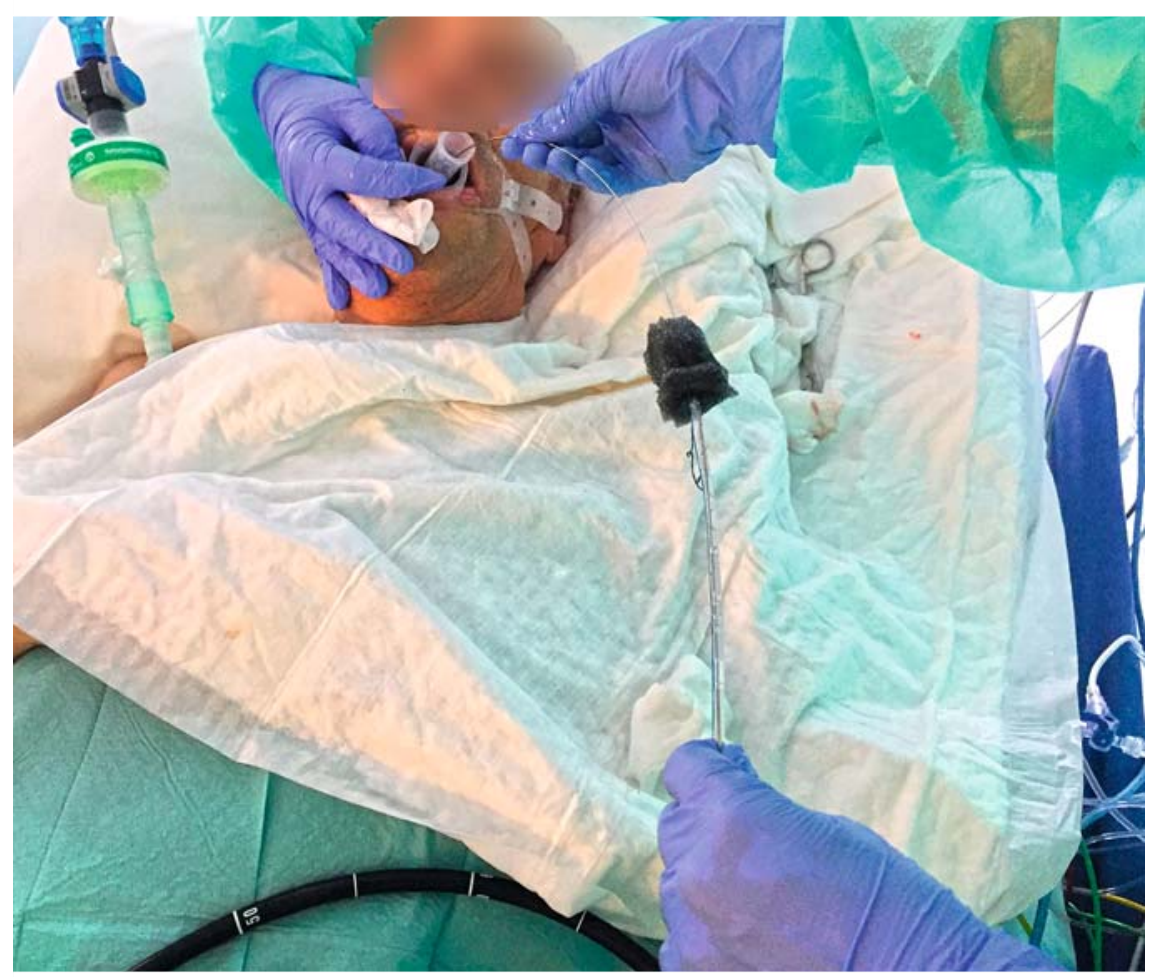

Fig. 4 The sponge is passed over the guidewire through the overtube. 


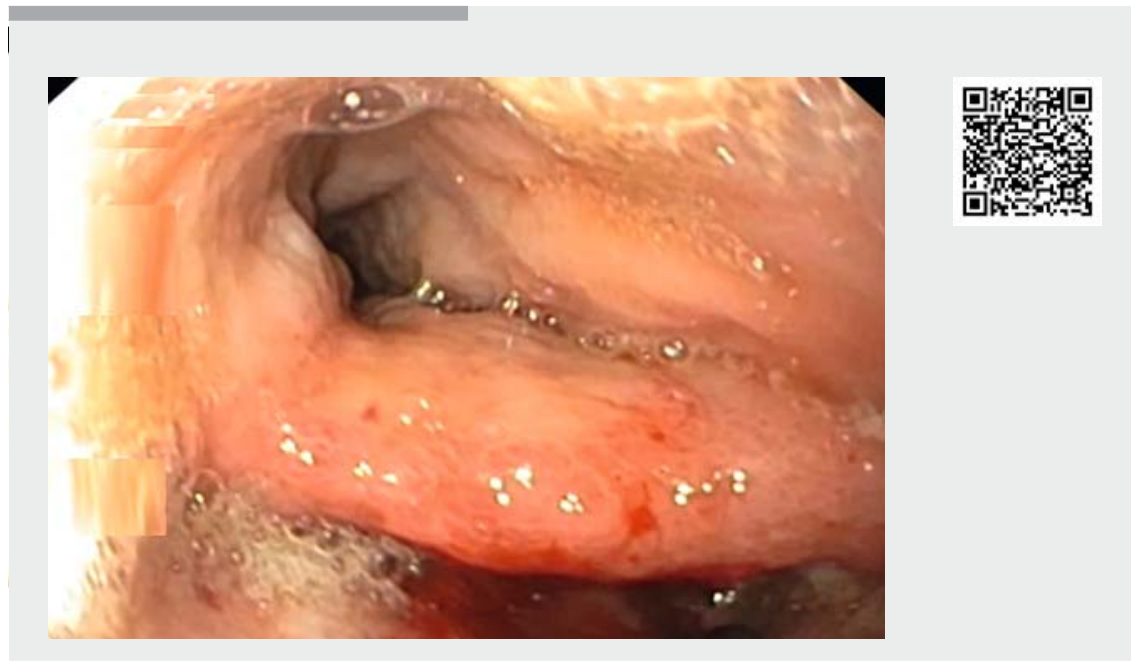

Video 1 Endoluminal vacuum-assisted therapy: combining guidewire with overtube technique.

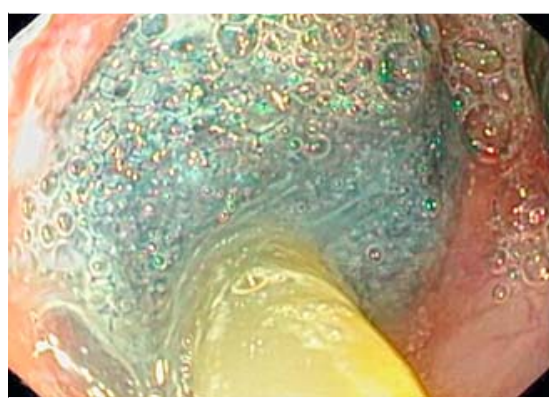

- Fig. 5 Sponge correctly placed into the deepest point of the cavity.

passed over the guidewire through the overtube ( $\mathbf{F i g . 4}$ ) and pushed into the cavity using a pushing probe. The final position of the sponge was confirmed endoscopically ( $\mathbf{F i g . 5}$ ).

The sponge was replaced every 3 to 4 days for 8 weeks with gradual debridement and reduction of the cavity.

This technique guarantees that the sponge is correctly placed into the cavity, avoiding the need to adjust the position with endoscopic forceps, which can be extremely challenging.
[1] Loske G, Muller CT. Tipps and Tricks in der Endoskopischen Unterdruck Therapie. Chirurg 2018; 89: $887-895$

[2] Newton NJ, Sharrock A, Rickard R et al. Systematic review of the use of endoluminal topical negative pressure in oesophageal leaks and perforations. Dis Esophagus 2017; 30: $1-5$

[3] Laukoetter MG, Mennigen R, Neumann PA et al. Successful closure of defects in the upper gastrointestinal tract by endoscopic vacuum therapy (EVT): a prospective cohort study. Surg Endosc 2017; 31: 2687-2696

[4] Bludau M, Fuchs HF, Herbold T et al. Results of endoscopic vacuum-assisted closure device for treatment of upper GI leaks. Surg Endosc 2018; 32: 1906 - 1914

[5] Pines G, Bar I, Elami A et al. Modified Endoscopic Vacuum Therapy for Nonhealing Esophageal Anastomotic Leak: Technique Description and Review of Literature. J Laparoendosc Adv Surg Tech A 2018; 28 : 33 40

Endoscopy_UCTN_Code_CPL_1AM_2AG

Competing interests

None

The authors

Sofia Saraiva, Susana Mão-de-Ferro, Isadora Rosa, António Dias Pereira

Department of Gastroenterology, Instituto Português de Oncologia de Lisboa Francisco Gentil EPE, Lisboa, Portugal

\section{Corresponding author}

\section{Sofia Saraiva}

Serviço de Gastrenterologia, Pavilhão Central Piso 3, Rua Professor Lima Basto, Pavilhão Central, 1099-023 Lisbon, Portugal Fax: +351-96-5102015

asofia.saraiva@gmail.com
DOI https://doi.org/10.1055/a-1011-3646

Published online: 27.9.2019

Endoscopy 2020; 52: E92-E93

(c) Georg Thieme Verlag KG

Stuttgart · New York

ISSN 0013-726X

\section{ENDOSCOPY E-VIDEOS}

https://eref.thieme.de/e-videos

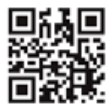

Endoscopy E-Videos is a free access online section, reporting on interesting cases and new

techniques in gastroenterological endoscopy. All papers include a high quality video and all contributions are freely accessible online.

This section has its own submission website at https://mc.manuscriptcentral.com/e-videos 